\title{
A Biosensor Based on Immobilization of Horseradish Peroxidase in Chitosan Matrix Cross-linked with Glyoxal for Amperometric Determination of Hydrogen Peroxide
}

\author{
Huai-Sheng Wang*, Qian-Xiu Pan and Gui-Xiang Wang \\ Department of Chemistry, Institute of Analytical Chemistry, Liaocheng University, Liaocheng, 252059
} China

* Corresponding author. E-mail: hswang@lctu.edu.cn

Received: 25 June 2004 / Accepted: 14 November 2004 / Published: 4 May 2005

\begin{abstract}
An amperometric biosensor for hydrogen peroxide $\left(\mathrm{H}_{2} \mathrm{O}_{2}\right)$ was developed via an easy and effective enzyme immobilization method with the "sandwich" configuration: ferrocene-chitosan: HRP: chitosan-glyoxal using a glassy carbon electrode as the basic electrode. In order to prevent the loss of immobilized HRP under optimized conditions, the biosensor surface was cross-linked with glyoxal. Ferrocene was selected and immobilized on the glassy carbon electrode surface as a mediator. The fabrication procedure was systematically optimized to improve the biosensor performance. The biosensor had a fast response of less than $10 \mathrm{~s}$ to $\mathrm{H}_{2} \mathrm{O}_{2}$, with a linear range of $3.5 \times 10^{-5}$ to $1.1 \times 10^{-3} \mathrm{M}$, and a detection limit of $8.0 \times 10^{-6} \mathrm{M}$ based on $\mathrm{S} / \mathrm{N}=3$.
\end{abstract}

Keywords: horseradish peroxidase, biosensor, hydrogen peroxide, chitosan

\section{Introduction}

The determination of hydrogen peroxide is of practical importance in chemical, biological and clinical as well as many other fields. Extensive techniques have been developed for this purpose, amongst which peroxidase modified electrodes are frequently used in recent years, particularly horseradish peroxidase (HRP). In order to improve the stability and activity of the enzyme immobilized on electrode surface, a variety of methods have been tried such as adsorption, entrapment 
in a porous matrix, covalent binding and electrochemical copolymerization. Immobilization of enzyme may lead to changes in enzyme structure and hence causes the kinetics, stability and specificity differing from that of the enzyme in homogeneous solution [1]. Therefore, great interest is devoted to find immobilization matrix, which can retain its specific biological function. In recent years, there has been a significant increase of interest in using natural polymers as an immobilization matrix for enzymes, living organisms, cell carriers. Different types of polysaccharides such as agar [2], alginate [3], carrageenan [4], chitin [5] and chitosan [6] have been used as immobilization matrices. Chitosan, a copolymer of glucosamine and $\mathrm{N}$-acetyglucosamine units linked by 1-4 glucosidic bonds, can be obtained by N-deacetylation of chitin, which is the second most abundant natural polymer [7]. Chitosan was selected as the matrix for immobilization of the enzyme because of an unusual combination of its properties, which includes an excellent membrane-forming ability, high permeability toward water, good adhesion, biocompatibility, non-toxicity and high mechanical strength. In addition, chitosan has the susceptibility to chemical modifications due to the abundant in amino groups, which not only facilitate the immobilization of enzymes in chitosan by covalent binding [8] but also adsorb metal ions [9-13] and various organic halogen substances [14,15], then prevents the enzyme from damage. Moreover, chitosan can form a thermally and chemically inert film that is insoluble in water. So chitosan has been widely used in the preparation of sensors in recent years [1,16-22].

Glutaraldehyde was usually used as a protein cross-linking agent in the fabrication of biosensor [6], while little use of glyoxal can be found in this area. The present work was attempt to develop a simple and robust amperometric hydrogen peroxide biosensor based on HRP immobilized by chitosan film cross-linked with glyoxal. We selected the "sandwich" configuration: ferrocene-chitosan: HRP: chitosan-glyoxal. The chitosan film cross-linked with glyoxal permitted high enzyme loadings due to the cross-linking reaction between the amino group of chitosan and aldehyde group of glyoxal. This cross-linking reaction simultaneously improves the stability of the chitosan film. There was no obvious redox reaction between the HRP and the $\mathrm{H}_{2} \mathrm{O}_{2}$ if no electron mediators existed in the redox system. Among the various mediators, ferrocene is a satisfactory candidate for the amperometric hydrogen peroxide sensor by measuring the reduction current. The one-electron oxidation of ferrocene to the stable ferricenium cation is a simple electron transfer reaction, in that there are no complications arising from adsorption or associated chemical reactions [23]. Therefore, ferrocene is utilized as the mediator for the determination of hydrogen peroxide in many studies [24-30], although the ferricinium as the water-soluble oxidized form of ferrocene is easily leached out from the electrode surface and leads to the instability of the enzyme electrode. In this study, ferrocene and HRP were immobilized on the glassy carbon electrode surface in sequence. We expected that the good membrane-forming ability of chitosan could improve the stability of ferrocene on the electrode. As a mediator, ferrocene accelerated the redox reaction. The mechanism of the electrons transfer is as the following:

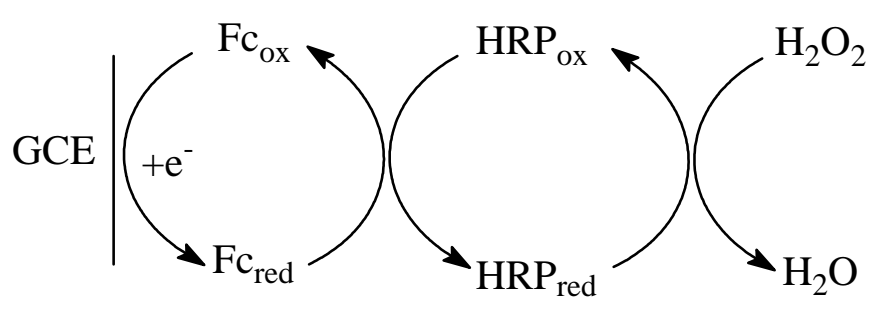




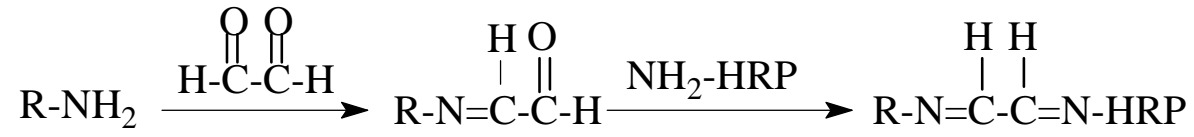
chitosan

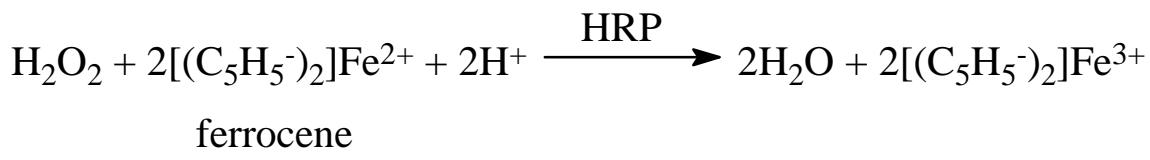

\section{Experimental}

\subsection{Apparatus and reagents}

HRP (EC 1.11.1.7, RZ > 3.0, $250 \mathrm{u} / \mathrm{mg}$ ) was purchased from ACROS; chitosan (MW 5.8×105 , 90.7\% deacetylation) was made from chitin (ACROS). The other chemicals were of analytical grade and used without further purification. The supporting electrolyte was $0.02 \mathrm{M}$ phosphate buffer (PBS) of pH 7.0. All aqueous solutions were prepared in doubly distilled water.

Electrochemical measurements were performed with a three-electrode system comprising a platinum wire as auxiliary electrode, a saturated calomel electrode as reference electrode, against which all potentials were quoted, and the modified glassy carbon electrode (3.0 mm diameter) as working electrode. The electrodes were connected to a 273A Potentiostat/Gawanostat (EG\&G, USA). All electrochemical experiments were carried out in a conventional electrochemical cell holding $10.0 \mathrm{~mL}$ PBS at room temperature. In addition, the ferrocene-modified electrode exhibited almost the same response in air-saturated and nitrogen-bubbled hydrogen peroxide solution, which suggested that the ferrocene-mediated biosensor was insensitive to the presence of dissolved oxygen. Therefore, all the electrochemical processes were in aerated solutions. A magnetic stirrer and a bar provided convective transport during the amperometric experiments.

\subsection{Procedures}

\subsubsection{Preparation of the enzyme electrode}

Chitosan solution (1.0\%) was prepared by dissolving chitosan powder in $0.8 \%$ acetic acid solution; the viscous solution was stirred at $250 \mathrm{rpm}$ for $3 \mathrm{~h}$ at room temperature. Glassy carbon electrodes were polished on a leather kit before each experiment with alumina slurry, rinsed thoroughly with doubly distilled water, then washed successively with acetone and doubly distilled water in ultrasonic bath and dried in air.

The biosensor was constructed with the following procedure: 1) $10.0 \mu \mathrm{L}$ of ferrocene ethanol solution ( $40 \mathrm{mM}$ ) was pipetted onto the surface of the electrode and dried in atmosphere. 2) $5.0 \mu \mathrm{L}$ of chitosan solution was dropped onto the surface of the electrode, and allowed to dry at room temperature. 3) $10.0 \mu \mathrm{L}$ of HRP solution (1.0 mg of HRP dissolved in $0.5 \mathrm{~mL}$ of 0.02 phosphate buffer, $\mathrm{pH}$ 7.0, containing $7 \mu \mathrm{L}$ of glycerol) was dropped onto the surface of the GCE, and distributed gently over the entire surface to ensure the complete coating of the GCE by the HRP solution (the presence of a small amount of glycerol in the enzyme solution acts as an emollient). Then, the electrode was left to dry at $4^{\circ}$ C. 4) $5.0 \mu \mathrm{L}$ of chitosan solution was dropped to the above dried layer to stabilize and prevent 


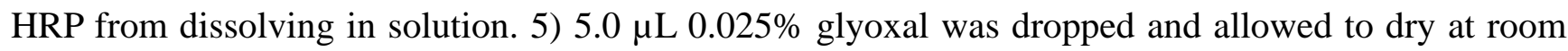
temperature. Finally, the biosensor was immersed in a pH 7.0 phosphate buffer and kept at $4{ }^{\circ} \mathrm{C}$ overnight to remove the excess HRP from the electrode surface. The biosensor was stored in $\mathrm{pH} 7.0$ phosphate buffer at $4{ }^{\circ} \mathrm{C}$ when it was not used.

\subsubsection{Measuring procedure}

Cyclic voltammetric experiments were performed in an unstirred solution at a scan rate of $100 \mathrm{mV} \mathrm{s}^{-1}$. In amperometric experiments, $-100 \mathrm{mV}$ was selected as the applied potential, moreover, a steady-state background current had to be obtained before $\mathrm{H}_{2} \mathrm{O}_{2}$ standard solution was added into the stirred buffer solution.

\section{Results and discussion}

\subsection{Optimization of experimental variables}

Ferrocene as a mediator, the effect of its concentration on the biosensor response was investigated by varying the concentration of mediator (10.0-50.0 mM). As shown in Fig. 1, the biosensor response to $\mathrm{H}_{2} \mathrm{O}_{2}$ increased sharply with the increase of ferrocene concentration from 10 to $40 \mathrm{mM}$. Typically, when the mediator concentration was low, the biosensor response was limited by the enzyme-mediator kinetics. A further increase of the concentration of mediator resulted in a slight decrease in current response as the response signal was limited by the enzyme-substrate kinetics. Thus, the concentration of mediator was fixed at $40.0 \mathrm{mM}$ for all the subsequent experiments.

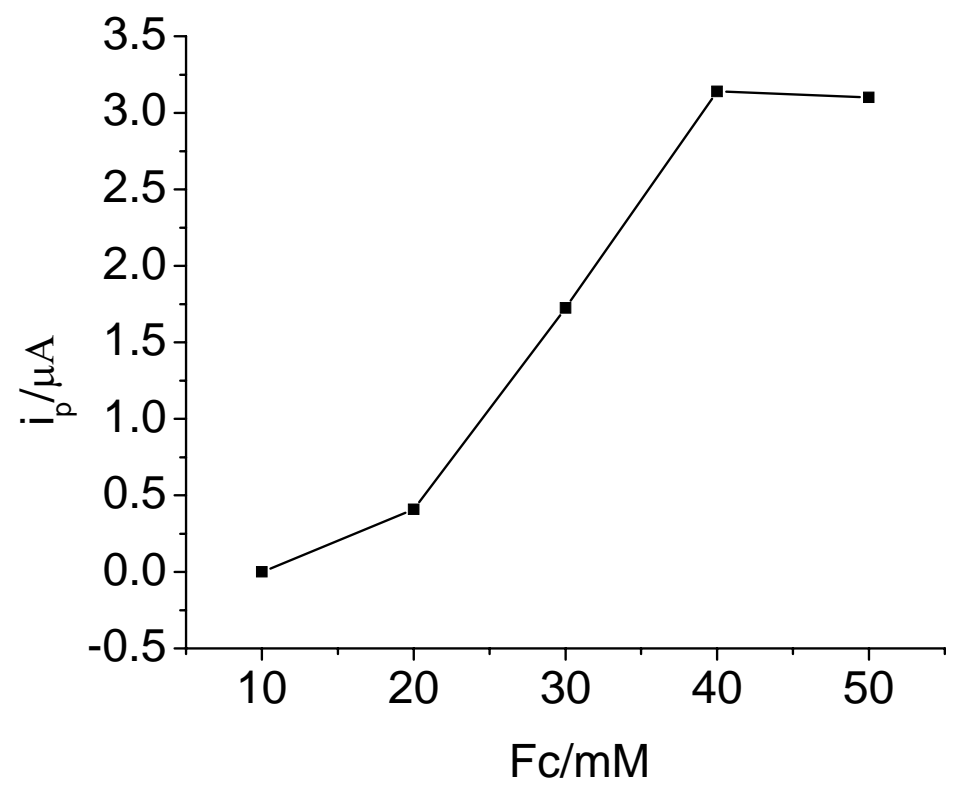

Figure 1. Influence of ferrocene concentration on the biosensor response studied by amperometric measurement for $9.68 \times 10^{-5} \mathrm{M} \mathrm{H}_{2} \mathrm{O}_{2}$ in $10.0 \mathrm{~mL} 0.02 \mathrm{M}$ phosphate buffer solution ( $\mathrm{pH} 7.0$ ).

The effect of applied potential on the biosensor response was tested and the results are shown in Fig. 2. The biosensor response to $\mathrm{H}_{2} \mathrm{O}_{2}$ increased with the change of applied potential from $-200 \mathrm{mV}$ to 
$100 \mathrm{mV}$. The highest sensitivity was obtained at $-100 \mathrm{mV}$. A further increase of the anodic potential resulted in decrease in current response and then $-100 \mathrm{mV}$ was selected as the applied potential in amperometric detection.

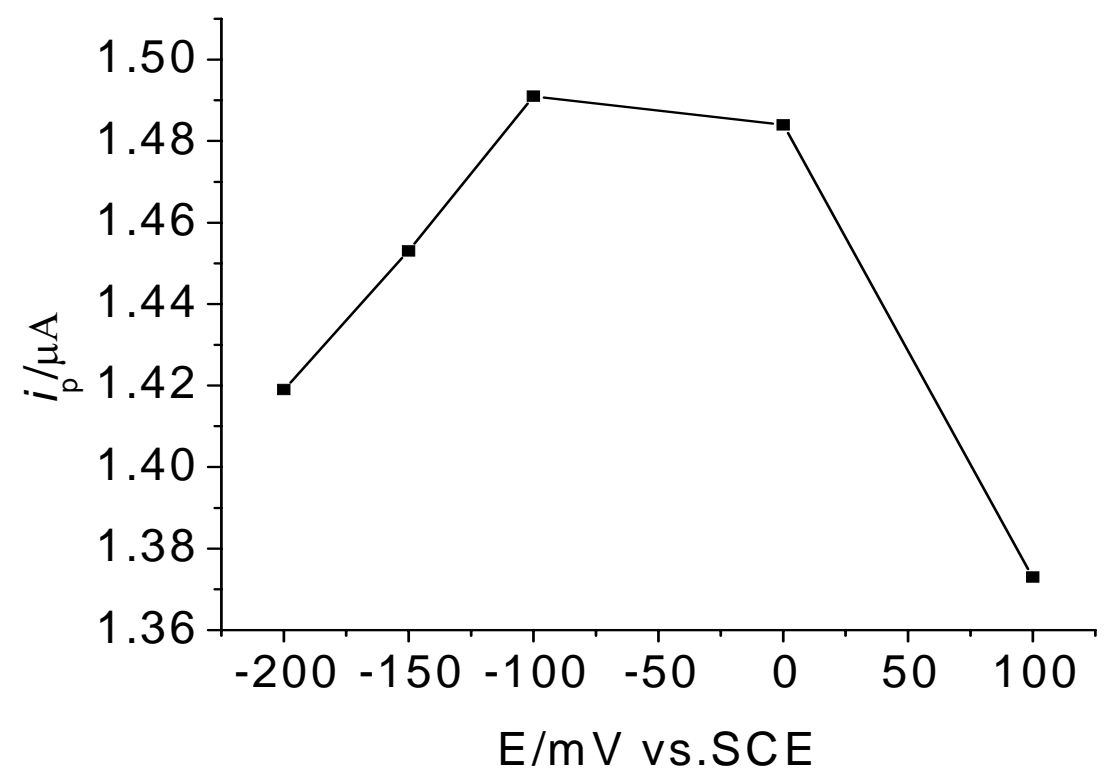

Figure 2. Effect of applied potential on the biosensor response studied by amperometric measurement for $9.68 \times 10^{-5} \mathrm{M} \mathrm{H}_{2} \mathrm{O}_{2}$ in $10.0 \mathrm{~mL} 0.02 \mathrm{M} \mathrm{pH}$ 7.0 PBS.

The effect of the $\mathrm{pH}$ of supporting electrolyte on the biosensor response was tested in the range of 6.0 to 8.5 , as shown in Fig. 3.

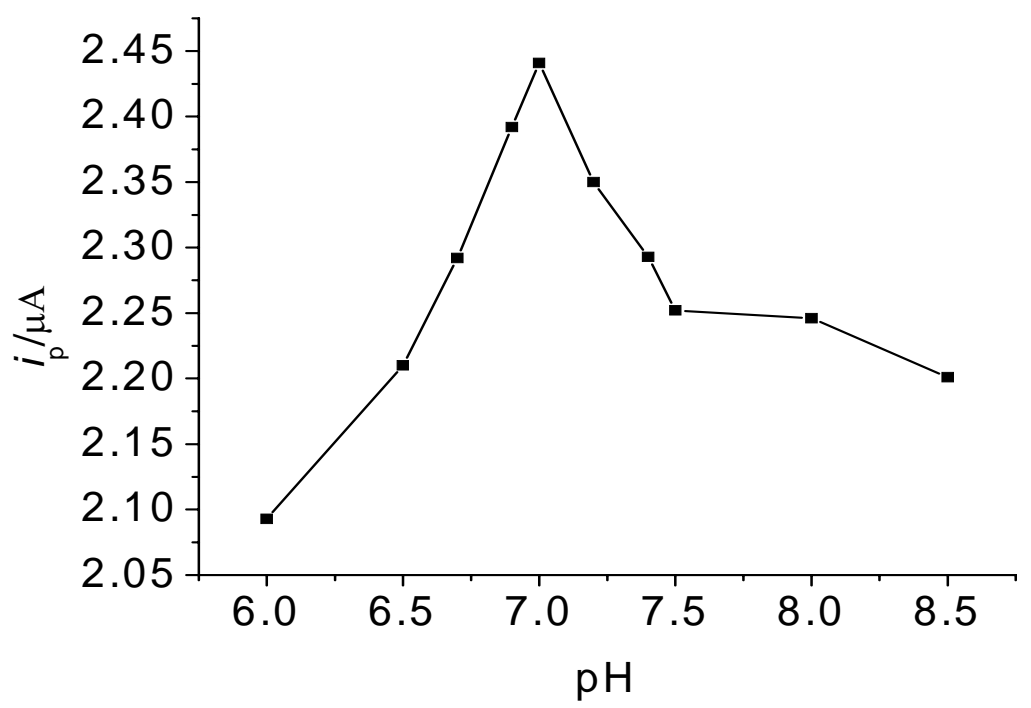

Figure 3. Effect of $\mathrm{pH}$ of the buffer solution on the biosensor response was tested with various $\mathrm{pH}$ values containing $4.84 \times 10^{-5} \mathrm{M} \mathrm{H}_{2} \mathrm{O}_{2}$.

From the graph, $\mathrm{pH} 7.0$ was easily selected for the remainder of the experiments. Moreover, $\mathrm{pH} 7.0$ is close to the optimum $\mathrm{pH}$ observed for soluble peroxidase [31] and avoids the possible dissolution of the chitosan film under the acidic conditions. 
The effect of the concentration of chitosan used for the preparation of the biosensor was investigated by varying the concentration with $0.25 \%, 0.5 \%$ and $1.0 \%$, which is shown in Fig. 4.

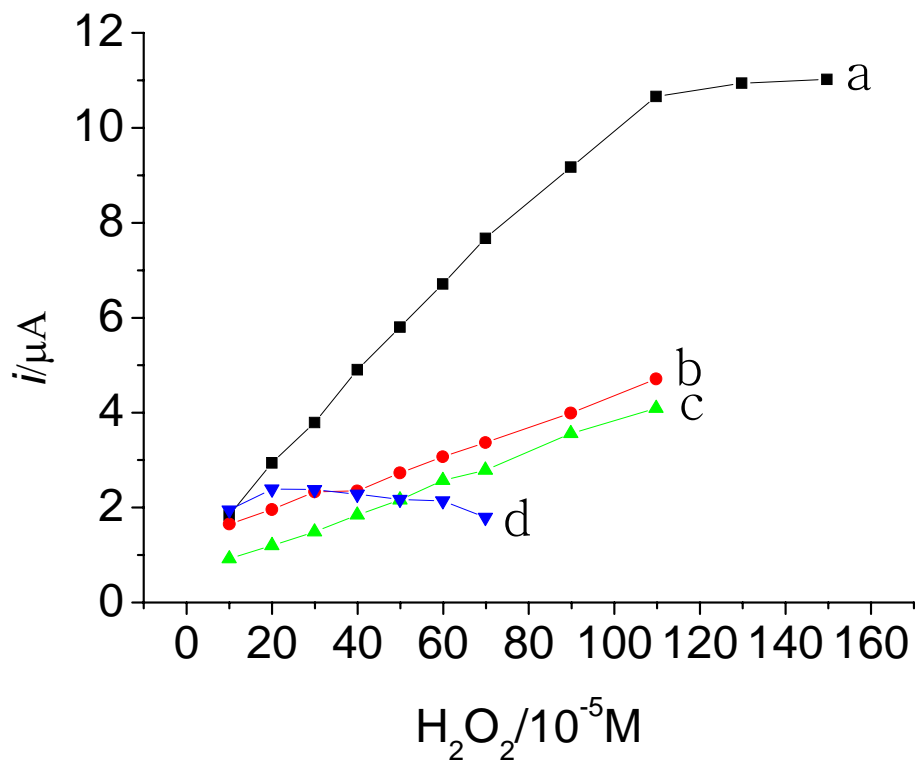

Figure 4. Effect of the chitosan concentration and glyoxal on the biosensor response studied by calibration plots for $\mathrm{H}_{2} \mathrm{O}_{2}$ in $10.0 \mathrm{~mL} 0.02 \mathrm{M} \mathrm{pH}$ 7.0 PBS. The chitosan film was prepared with a solution: (a) $1 \%$ chitosan with $0.025 \%$ glyoxal; (b) $0.5 \%$ chitosan with $0.025 \%$ glyoxal; (c) $0.25 \%$ chitosan with $0.025 \%$ glyoxal and (d) $1 \%$ chitosan without glyoxal.

Because higher concentration of acetic acid would not be favorable for enzyme immobilization, the concentration of acetic acid used for preparing chitosan solution was relatively low $(0.8 \%)$. Thus, a thicker chitosan film was not tried, as it was difficult to prepare more concentrated chitosan solution with the acetic acid (0.8\%). Furthermore, if the concentration of chitosan was higher and the immobilization film was thicker, it would lead to a higher diffusion barrier for the substrate and mediator. However, when the concentration of chitosan was low, the amount of immobilized enzyme was low, and the response of the biosensor was low and saturated rather early. It can be seen from Fig. 4, the biosensor prepared with $1.0 \%$ chitosan solution and $0.025 \%$ glyoxal (curve a) had a higher current response and wider linear response range than that prepared with $1.0 \%$ chitosan solution without glyoxal (curve d). It can be seen also that the response of the biosensor decreased with the decreasing of chitosan concentration in the presence of $0.025 \%$ glyoxal (curve b and c). The above results suggest that the improvement of response in the presence of glyoxal could be due to the cross-linking reactions between the amino groups of chitosan and the aldehyde groups of glyoxal, and amino groups of HRP and the aldehyde groups of glyoxal. More amino groups in $1.0 \%$ chitosan solution can be cross-linked with the aldehyde groups and thus more HRP can be immobilized on the biosensor. HRP and chitosan could not be cross-linked directly except via the glyoxal acting as a "bridge". Nevertheless, the activity of the enzyme and the stability of the biosensor would be damaged if the concentration of the glyoxal were too high. Therefore, we selected $0.025 \%$ glyoxal as the cross linker. 


\subsection{Voltammetric behavior of the enzyme electrode}

The electrochemical behavior of the enzyme electrode was studied using cyclic voltammetry. Fig. 5 shows the cyclic voltammograms of the ferrocene-modified GCE (a) and ferrocene-modified enzyme GCE (b) in $0.02 \mathrm{M}$ pH 7.0 phosphate buffer solution.

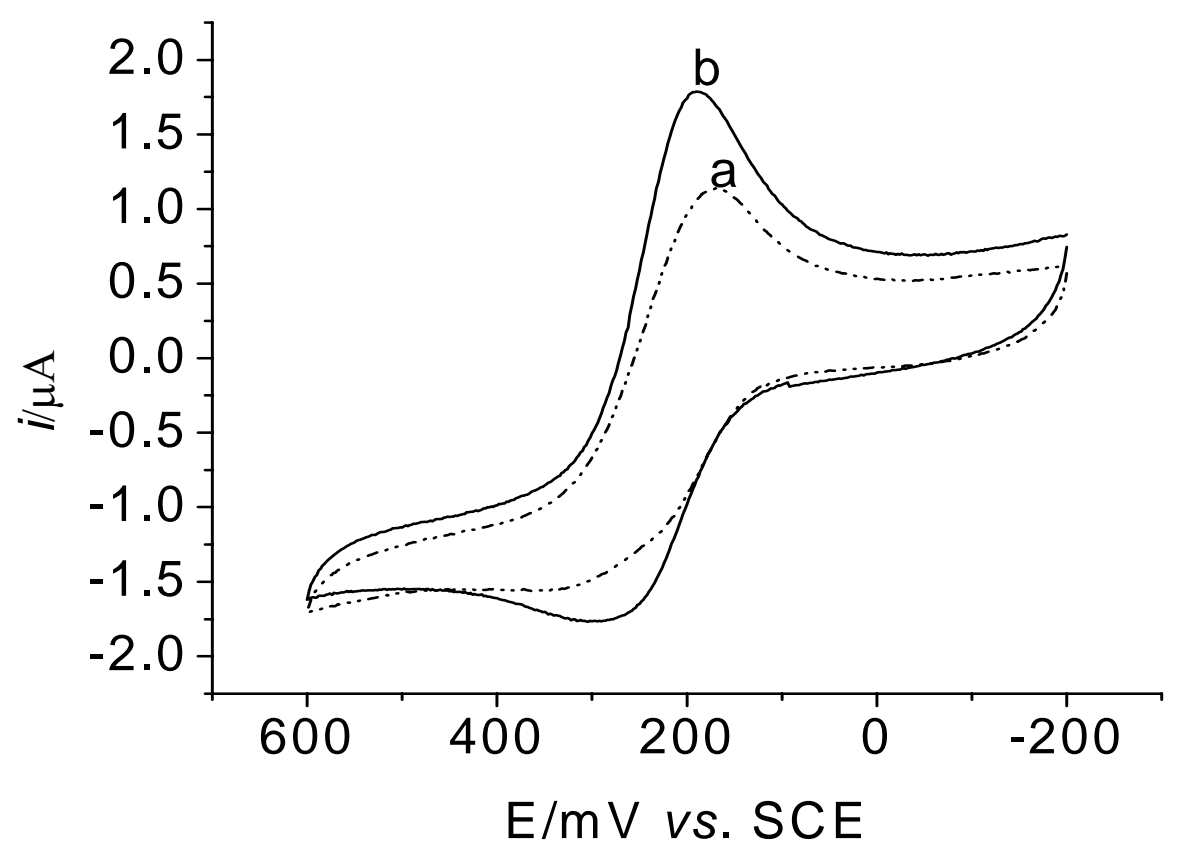

Figure 5. Cyclic voltammograms of CS/Fc electrode (a) and CS/HRP/Fc (b) obtained in $10.0 \mathrm{~mL}$ $0.02 \mathrm{M} \mathrm{pH} 7.0$ PBS. Scan rate $100 \mathrm{mV} \mathrm{s}^{-1}$.

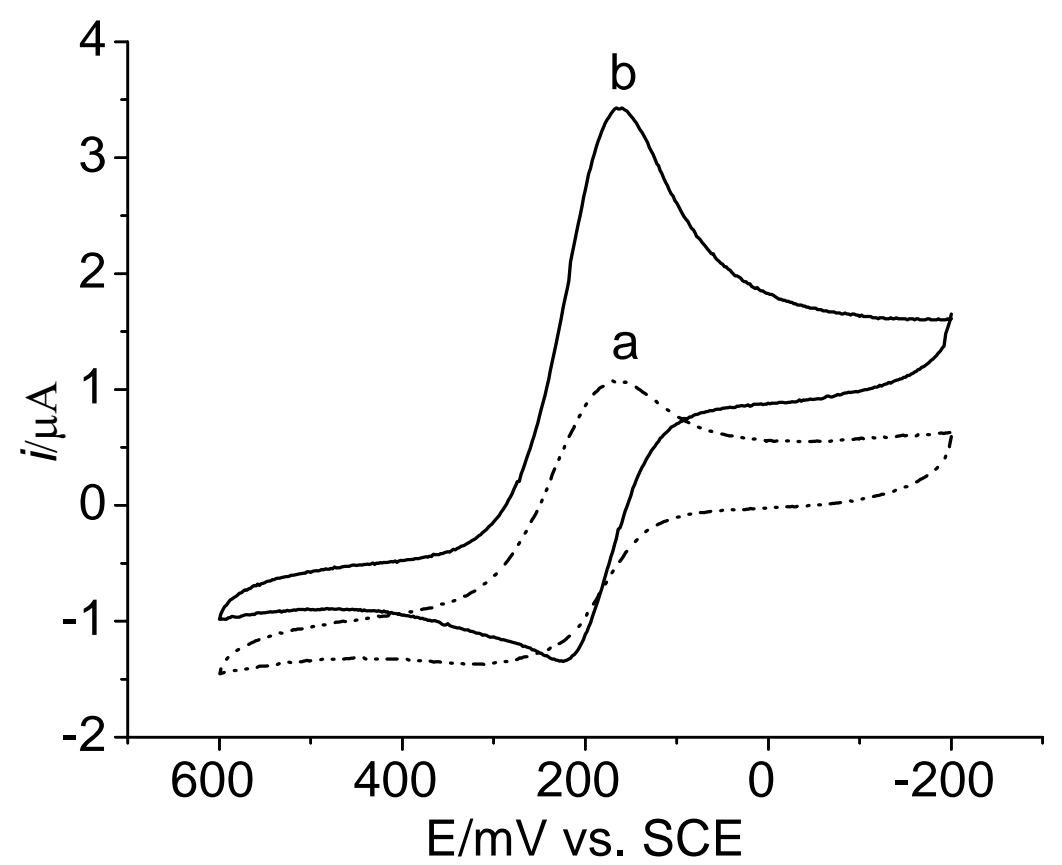

Figure 6. Cyclic voltammograms of CS/Fc electrode (a) and CS/HRP/Fc (b) in $10.0 \mathrm{~mL} 0.02 \mathrm{M} \mathrm{pH}$ 7.0 PBS containing $1.94 \times 10^{-4} \mathrm{M} \mathrm{H}_{2} \mathrm{O}_{2}$. Scan rate $100 \mathrm{mV} \mathrm{s}^{-1}$. 
It can be seen that both the electrodes have only one pair of quasi-reversible redox peaks of ferrocene and the redox peak currents are increased slightly in the presence of HRP. Thus, the presence of HRP is in favor of the electron transfer between ferrocene and electrode surface. The cyclic voltammograms of the ferrocene-modified electrode and ferrocene-modified enzyme electrode in 0.02 $\mathrm{M}$ pH 7.0 phosphate buffer solution in the presence of $\mathrm{H}_{2} \mathrm{O}_{2}$ are shown in Fig. 6. The cathodic peak current of the ferrocene-modified enzyme electrode was increased significantly when $1.94 \times 10^{-4} \mathrm{M}$ $\mathrm{H}_{2} \mathrm{O}_{2}$ was added (b), which indicates that $\mathrm{H}_{2} \mathrm{O}_{2}$ oxidizes $\mathrm{Fc}_{\mathrm{red}}$ to $\mathrm{FC}_{\mathrm{ox}}$ in the presence of HRP, and the $\mathrm{FC}_{\mathrm{ox}}$ is subsequently reduced at the electrode surface. No obvious increase of the cathodic peak current of the ferrocene-modified electrode was observed in the presence of $1.94 \times 10^{-4} \mathrm{M} \mathrm{H}_{2} \mathrm{O}_{2}$ (a). These results suggest that HRP can be immobilized well in the chitosan film and remain its bioactivity.

\subsection{Amperometric response of the HRP electrodes}

Fig. 7 shows the typical current-time response of the HRP biosensor for successive additions of $\mathrm{H}_{2} \mathrm{O}_{2}$ under the optimized experimental conditions. It is clear that a rapid and sensitive response to $\mathrm{H}_{2} \mathrm{O}_{2}$ is achieved.

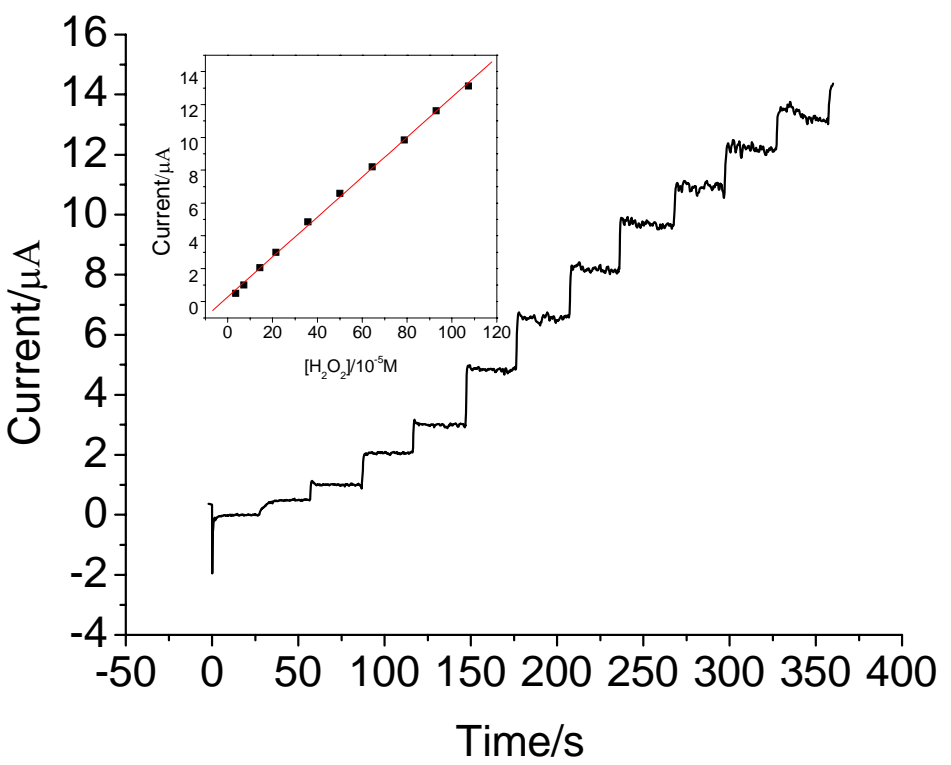

Figure 7. A typical current-time response curve for successive additions of 10, 10, 20, 20, 40, 40, 40, 40, 40, 40 and $50 \mu \mathrm{L} 35.8 \mathrm{mM} \mathrm{H}_{2} \mathrm{O}_{2}$ for the enzyme electrode in $10.0 \mathrm{~mL} 0.02 \mathrm{M} \mathrm{pH} 7.0$ PBS. Applied potential: $-100 \mathrm{mV}$. The insert plot shows a calibration curve of current with $\mathrm{H}_{2} \mathrm{O}_{2}$ concentration.

The insert plot shows that the response of the biosensor to $\mathrm{H}_{2} \mathrm{O}_{2}$ has a linear relationship in the range of $3.5 \times 10^{-5}$ to $1.1 \times 10^{-3} \mathrm{M}$ with the regression equation: $i_{\mathrm{p}} / \mu \mathrm{A}=1.22 \times 10^{4} c+0.29(\mathrm{c}$ in $\mathrm{M}, r=$ 0.9998). The detection limit of the biosensor was found to be $8.0 \times 10^{-6} \mathrm{M}$ based on $\mathrm{S} / \mathrm{N}=3$ and the sensitivity of the biosensor was $172.4 \mu \mathrm{A} \mathrm{mM}^{-1} \mathrm{~cm}^{-2}$ which was higher than that reported before [32]. The apparent Michaelis-Menten constant $\left(K_{\mathrm{m}}{ }^{\mathrm{app}}\right)$ is calculated to be $2.0 \mathrm{mM}$ according to the Lineweaver-Burk equation, which was smaller than those reported for HRP immobilized by sol-gel/hydrogel film [33]. The high sensitivity and the small $K_{\mathrm{m}}{ }^{\text {app }}$ mean that the immobilized HRP possessed a higher enzymatic activity. When the concentration of $\mathrm{H}_{2} \mathrm{O}_{2}$ was $3.1 \times 10^{-4} \mathrm{M}$, the relative 
standard deviation of six successive determinations was $4.1 \%(n=6)$ with a mean current of $4.2 \mu$ A.

\subsection{Selectivity against interference and storage stability}

Eight possible interfering substances were used to evaluate the selectivity of the HRP electrode. The current obtained for each interfering substance at a concentration of $1.0 \mathrm{mM}$ in the presence of $4.26 \times 10^{-5} \mathrm{M} \mathrm{H}_{2} \mathrm{O}_{2}$ was used as an indicator for the enzyme electrode selectivity in comparison with the $\mathrm{H}_{2} \mathrm{O}_{2}$ alone. The results of the interference study are listed in Table 1. Glucose, sucrose, citric acid, oxalic acid, cysteine, nitrate and fluride did not cause any observable interference except ascorbic acid. Ascorbic acid can reduce the $\left(\mathrm{C}_{5} \mathrm{H}_{5}{ }^{-}\right) \mathrm{Fe}^{3+}$ produced in the peroxidase catalyzed reaction and thus, interferes in the determination of $\mathrm{H}_{2} \mathrm{O}_{2}$.

The stability of the HRP sensor was investigated by amperometric measurements in the presence of $\mathrm{H}_{2} \mathrm{O}_{2}$. No decrease of current was observed after the electrode was tested 20 times continuously. Another, the sensor's stability was examined with intermittent measuring the current response to $\mathrm{H}_{2} \mathrm{O}_{2}$ standard solution every 5 days in the period of 1 month. The catalytic current response could retain about $75 \%$. The decrease of the current response may be due to the leach of ferrocene from the electrode surface to solution.

Table 1. Possible interferences tested with the enzyme biosensor.

\begin{tabular}{ll}
\hline Possible interference & Current ratio $^{\mathrm{a}}$ \\
\hline Ascorbic acid & 0.21 \\
Cysteine & 0.86 \\
Sucrose & 0.97 \\
Citric acid & 0.98 \\
Nitrate & 0.99 \\
Glucose & 1.00 \\
Fluride & 1.00 \\
Oxalic acid & 1.00 \\
\hline
\end{tabular}

${ }^{\mathrm{a}}$ Ratio of currents for mixtures containing $1.0 \mathrm{mM}$ interfering substance and $4.26 \times 10^{-5} \mathrm{M} \mathrm{H}_{2} \mathrm{O}_{2}$ to that for $4.26 \times 10^{-5} \mathrm{M} \mathrm{H}_{2} \mathrm{O}_{2}$ alone.

\section{Conclusions}

In this article, we introduced a new type of amperometric $\mathrm{H}_{2} \mathrm{O}_{2}$ biosensor based on the immobilization of HRP and ferrocene in chitosan matrices with a "sandwich" configuration. The abundant amino groups present in chitosan provide a biocompatible environment for HRP immobilization. The developed HRP sensor exhibits high sensitivity and a fast response to $\mathrm{H}_{2} \mathrm{O}_{2}$. Moreover, it also shows a very good reproducibility and stability.

\section{References}

1. Wang, G.; Xu, J.J.; Chen, H.Y. Amperometric Hydrogen Peroxide Biosensor with 
Sol-Gel/Chitosan Network-like Film as Immobilization Matrix. Biosens. Bioelectron. 2003, 18, 335-343.

2. Ziegler, W.; Gaburjakova, J.; Gaburjakova, M. Agar-Supported Lipid Bilayers- Basic Structures for Biosensor Design. Electrical and mechanical properties. Colloid. Surf. A. 1998, 140, 357-367.

3. Mousty, C.; Lepellec, A.; Cosnier, S.; Novoa, A. Fabrication of Organic Phase Biosensor Based on Multilayered Polyphenol Oxidase Protected by an Alginate Coating. Electrochem. Commun. 2001, 3, 727-732.

4. Tziboula, A.; Horne, D.S. Influence of Whey Protein Denaturation on $k$-Carrageenan Gelation. Colloid. Surf. B. 1999, 12, 299-308.

5. Sugawara, K.; Fukushi, H.; Hoshi, S.; Akatsuka, K. Electrochemical Sensing of Glucose at a Platinum Electrode with a Chitin/Glucose Oxidase Film. Anal. Sci. 2000, 16, 1139-1143.

6. Miao, Y.; Tan, S.N. Amperometric Hydrogen Peroxide Biosensor Based on Immobilization of Peroxidase in Chitosan Matrix Crosslinked with Glutaraldehyde. Analyst 2000, 125, 1591-1594.

7. Wan, Y.; Creber, K.A. M.; Peppley, B. Synthesis, Characterization and Ionic Conductive Properties of Phosphorylated Chitosan Membranes. Macromol. Chem. Phys. 2003, 204, 850-858.

8. Genta, I.; Constantini, M.; Asti, A. Influence of Glutaraldehyde on Drug Release and Mucoadhesive Properties of Chitosan Microspheres. Carbohydr. Polym. 1998, 36, 81-88.

9. Baba, Y.; Noma, H.; Nakayama, R.; Matsushita, Y. Preparation of Chitosan Derivatives Containing Methylthiocarbamoyl and Phenylthiocarbamoyl Groups and Their Selective Adsorption of Copper (II) over Iron (III). Anal. Sci. 2002, 18, 359-361.

10. Modrzejewska, Z.; Kaminski, W. Separation of Cr (VI) on Chitosan Membranes. Ind. Eng. Chem. Res., 1999, 38, 4946-4950.

11. Oshita, K.; Oshima, M.; Gao, Y.H.; Lee, K.H.; Motomizu, S. Adsorption Behavior of Mercury and Precious Metals on Cross-Linked Chitosan and the Removal of Ultratrace Amounts of Mercury in Concentrated Hydrochloric Acid by a Column Treatment with Cross-Linked Chitosan. Anal. Sci. 2002, 18, 1121-1125.

12. Gao, Y.H.; Lee, K.H.; Oshima, M.; Motomizu, S. Adsorption Behavior of MetalIons on Cross-linked Chitosan and the Determination of Oxoanions after Pretreatment with a Chitosan Column. Anal. Sci. 2000, 16, 1303-1308.

13. Baba, Y.; Noma, H.; Nakayama, R.; Matsushita, Y. Selective Adsorption of Mercury (II) on Chitosan Derivatives from Hydrochloric Acid. Anal. Sci. 1998, 14, 687-690.

14. Yao, X.; Lu, G.H.; Wu, X.G.; Zhan, T. Studies on Electrochemical Behavior of Bromide at a Chitosan-Modified Glassy Carbon Electrode. Electroanalysis 2001, 13, 923-926.

15. Rhee, J.S.; Jung, M.W.; Paeng, K.J. Evaluation of Chitin and Chitosan as a Sorbent for the Preconcentration of Phenol and Chlorophenols in Water. Anal. Sci. 1998, 14, 1089-1092.

16. Magalhaes, J.M.C.S.; Machado, A.A.S.C. Urea Potentiometric Biosensor Based on Urease Immobilized on Chitosan Membranes. Talanta 1998, 47, 183-191.

17. Miao, Y.; Tan, S.N. Amperometric Hydrogen Peroxide Biosensor with Silica Sol-Gel/Chitosan Film as Immobilization Matrix. Anal. Chim. Acta. 2001, 437, 87-93.

18. Miao, Y.; Chia, L.S.; Goh, N.K.; Tan, S.N. Amperometric Glucose Biosensor Based on Immobilization of Glucose Oxidase in Chitosan Matrix Cross-Linked With Glutaraldehyde. Electroanalysis 2001, 13, 347-349.

19. Chen, X.; Jia, J.B.; Dong, S.J. Organically Modified Sol-Gel/Chitosan Composite Based Glucose 
Biosensor. Electroanalysis 2003, 15, 608-612.

20. Cruz, J.; Kawasaki, M.; Gorski, W. Electrode Coatings Based on Chitosan Scaffolds. Anal. Chem. 2000, 72, 680-686.

21. Zhou, G..J.; Wang, G.; Xu, J.J.; Chen, H.Y. Reagentless Chemiluminescence Biosensor for Determination of Hydrogen Peroxide Based on the Immobilization of Horseradish Peroxidase on Biocompatible Chitosan Membrane. Sens. Actuat. B. 2002, 81, 334-339.

22. Bao, S.; Nomura, T.; Silver-selective Sensor Using an Electrode-Separated Piezoelectric Quartz Crystal Modified with a Chitosan Derivative. Anal. Sci. 2002, 18, 881-885.

23. Haymond, S.; Babcock, G.T.; Swain, G. M. Electron Transfer Kinetics of Ferrocene at Microcrystalline Boron-Doped Diamond Electrodes: Effect of Solvent and Electrolyte. Electroanalysis 2003, 15, 249-253.

24. Pandey, P.C.; Upadhyay, S.; Shukla, N.K.; Sharma, S. Studies on the Electrochemical Performance of Glucose Biosensor Based on Ferrocene Encapsulated ORMOSIL and Glucose Oxidase Modified Graphite Paste Electrode. Biosens. Bioelectron. 2003, 18, 1257-1268.

25. Pandey, P.C.; Upadhyay, S. Bioelectrochemistry of Glucose Oxidase Immobilized on Ferrocene Encapsulated Ormosil Modified Electrode. Sens. Actuat. B. 2001, 76, 193-198.

26. Nakabayashi, Y.; Wakuda, M.; Imai, H. Amperometric Glucose Sensors Fabricated by Electrochemical Polymerization of Phenols on Carbon Paste Electrodes Containing Ferrocene as an Electron Transfer Mediator. Anal. Sci. 1998, 14, 1069-1076.

27. Nakabayashi, Y.; Yoshikawa, H. Amperometric Biosensors for Sensing of Hydrogen Peroxide Based on Electron Transfer between Horseradish Peroxidase and Ferrocene as a Mediator. Anal. Sci. 2000, 16, 609-613.

28. Pandey, P.C.; Upadhyay, S.; Tiwari, I.; Singh, G. A Novel Ferrocene Encapsulated Palladium-Linked Ormosil-Based Electrocatalytic Dopamine Biosensor. Sens. Actuat. B. 2001, 75, 48-55.

29. Armada, M.P.G.; Losada, J.; Cuadrado, I. A Siloxane Homopolymer with Interacting Ferrocenes as a New Material for the Preparation of Sensors Based on the Detection of Hydrogen Peroxide. Electroanalysis 2003, 15, 1109-1114.

30. Yabuki, S.; Mizutani, F.; Hirata, Y. Glucose-Sensing Electrode Based on Glucose Oxidase-Attached Polyion Complex Membrane Containing Peroxidase and Ferrocene. Electroanalysis 2001, 13, 380-383.

31. Maehly, A.C. Plant Peroxidases: Methods in Enzymology; Academic Press: New York, 1955; Vol. 11, p. 807.

32. Zhang, J.Z.; Li, B.; Wang, Z.X.; Cheng, G.J.; Dong, S.J. Functionalized Inorganic-Organic Composite Material Derivated by Sol-Gel for Construction of Mediated Amperometric Hydrogen Peroxide Biosensor. Anal. Chim. Acta. 1999, 388, 71-78.

33. Wang, B.Q.; Zhang, J.Z.; Cheng, G.J.; Dong, S.J. Amperometric Enzyme Electrode for the Determination of Hydrogen Peroxide Based on Sol-Gel/Hydrogel composite film. Anal. Chim. Acta. 2000, 407, 111-118.

(C) 2005 by MDPI (http://www.mdpi.net). Reproduction is permitted for noncommercial purposes. 